\title{
Acesso vascular
}

\section{Vascular access}

Ana Paula de Carvalho Panzeri Carlotti

\begin{abstract}
RESUMO
Este texto aborda as prioridades de acesso vascular de acordo com o contexto clínico, as indicações, contraindicações e complicações dos diversos tipos de acesso vascular, e as técnicas de obtenção do acesso vascular periférico, intraósseo e central.
\end{abstract}

Palavras-chave: Acesso Venoso Periférico. Acesso Vascular Intraósseo. Acesso Venoso Central. Criança.

\section{Introdução}

A capacitação técnica para a obtenção de um acesso vascular é fundamental a todos os médicos. O acesso vascular é essencial à administração de fluidos e drogas durante o suporte avançado de vida, mas sua obtenção pode ser difícil no paciente gravemente doente. Durante a ressuscitação cardiopulmonar (RCP) e o tratamento do choque, o acesso de escolha é a veia periférica - de preferência, duas veias de grosso calibre, utilizando cateteres curtos e grossos (tipo cateter sobre agulha). Caso não se consiga obter o acesso venoso periférico prontamente em poucos minutos, a via intraóssea deve ser estabelecida, lembrando que ela pode ser obtida rapidamente em pacientes de todas as idades (inclusive em adultos). Logo após o início da ressuscitação, deve-se obter um acesso venoso central, que proporciona via segura para a administração de fluidos e drogas e possibilita a monitorização da pressão venosa central. Se as tentativas de obtenção de acesso venoso periférico, intraósseo e central não forem bem sucedidas, deve-se proceder à dissecção venosa. Durante a realização de qualquer procedimento invasivo, as precauções universais devem ser sempre seguidas. ${ }^{1}$

\section{Acesso venoso periférico}

As indicações de obtenção de acesso venoso periférico incluem a administração intravenosa de drogas e fluidos, a transfusão de hemoderivados e todas as outras situações em que o acesso direto à corrente sanguínea é necessário, como durante a realização de cirurgias e os cuidados de emergência. ${ }^{2} \mathrm{O}$ acesso venoso periférico proporciona uma via satisfatória para a administração de fluidos e drogas durante a RCP e o tratamento do choque, desde que seja estabelecido rapidamente em veia de grosso calibre. ${ }^{1}$

As contraindicações relativas da inserção de um cateter em veia periférica em um determinado local são infecção, flebite, esclerose de veias, infiltração intravenosa prévia, queimaduras ou lesões trau- 
máticas proximais ao local de inserção, fístula arteriovenosa no membro e procedimento cirúrgico afetando o membro. Em situações em que ocorre vasoconstrição intensa, como desidratação grave, choque e parada cardiorrespiratória, pode ser difícil obter um acesso venoso periférico. Assim, havendo impossibilidade de estabelecer um acesso venoso periférico ou em situações de emergência, em que a obtenção do acesso venoso periférico pode demorar muito, devese proceder à cateterização intraóssea ou central, ou à dissecção venosa. ${ }^{1,2}$

A escolha do local de cateterização venosa periférica deve levar em conta a idade, o conforto do paciente, a acessibilidade da veia em relação à posição do paciente e a urgência da situação. Em geral, dá-se preferência às veias dos membros superiores, pois elas são mais duráveis e se associam a menos complicações do que as veias dos membros inferiores. Os locais preferenciais de cateterização são as veias do antebraço, particularmente a veia cubital mediana, que atravessa a fossa antecubital e é frequentemente cateterizada em situações de urgência, pois acomoda cateteres calibrosos. Quando as veias dos membros superiores são inacessíveis, as veias dorsais dos pés ou as veias safenas nos membros inferiores podem ser utilizadas. Ressalta-se que a cateterização das veias dos membros inferiores se associa a maior risco de tromboembolismo. Entretanto, este risco é menor em lactentes e crianças do que em adultos. Locais alternativos de cateterização de veia periférica incluem as veias do couro cabeludo em recém-nascidos e lactentes jovens, e a veia jugular externa. Durante a RCP, as veias do couro cabeludo devem ser evitadas, pois sua cateterização pode interferir com as manobras de ressuscitação, além de haver maior risco de infiltração durante a administração rápida de líquidos e medicações. ${ }^{1,2}$

Os materiais necessários para a cateterização venosa periférica incluem luvas, óculos de proteção, garrote, solução antisséptica à base de clorexidina, gaze estéril, solução fisiológica em uma seringa, curativo oclusivo transparente e estéril, cateteres de tamanhos apropriados, bolsa de soro com equipo e recipiente especial para o descarte de agulhas. Pode ser necessário utilizar um anestésico local se o cateter for calibroso (maior ou igual a 20 gauge). Há vários tipos de cateteres, sendo os escalpes (ou "butterflies") (Figura 1) e os cateteres sobre agulha (Figura 2), os mais utilizados. $^{2}$
O tamanho do cateter depende do tamanho do vaso em relação à idade do paciente e da situação clínica. Cateteres mais finos oferecem menor resistência ao fluxo e se associam a menos complicações, enquanto que cateteres mais grossos são utilizados em situações agudas para ressuscitação hídrica. ${ }^{1,2}$

Antes de realizar a cateterização da veia periférica, deve-se explicar o procedimento ao paciente e informá-lo sobre possíveis complicações, como sangramento, formação de equimose e infecção. Se o local selecionado para a obtenção do acesso for o membro superior, o paciente deve ser colocado em posição supina, com o braço apoiado sobre uma superfície. $\mathrm{O}$ médico deve estar em posição confortável e a iluminação do ambiente deve ser apropriada. ${ }^{2}$

Inicialmente, coloca-se o garrote formando meio laço, 8 a $10 \mathrm{~cm}$ acima do local de inserção do cateter. A avaliação das veias disponíveis inclui a inspeção e a palpação. Caso haja dificuldade de visualizar a veia,

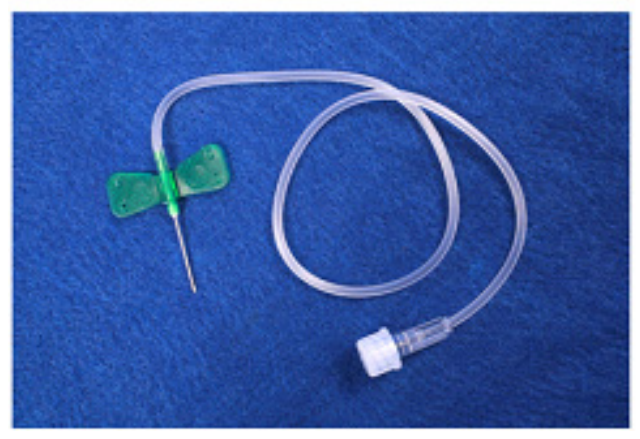

Figura 1: Escalpe (butterfly).

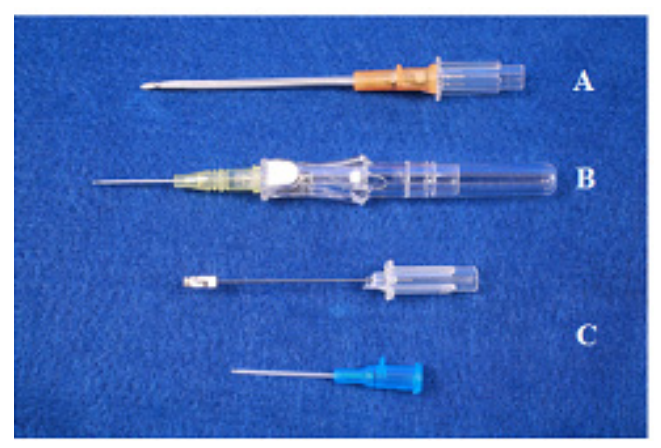

Figura 2: A. Cateter sobre agulha. B. Cateter sobre agulha com dispositivo de proteção contra acidentes pérfuro-cortantes controlado pelo usuário. O botão branco, quando pressionado, encapsula a agulha após o cateter ser inserido na veia. C. Cateter sobre agulha com dispositivo de segurança auto-acionável, mostrando a agulha com o dispositivo de proteção (acima) e o cateter (abaixo). O dispositivo de segurança é automaticamente acionado assim que se remove a agulha. 
vários métodos podem ser usados para dilatá-la, como posicionar o braço abaixo do nível do coração, dar "tapinhas" na veia, pedir para o paciente abrir e fechar a mão repetidamente ou aplicar uma compressa morna sobre o local selecionado para induzir vasodilatação. A ultrassonografia também pode ser útil para ajudar a localizar a veia. ${ }^{2}$

Após selecionar a veia, faz-se a limpeza do local com solução antisséptica à base de clorexidina, com movimentos circulares, de dentro para fora, deixando a área secar completamente. Após a antissepsia, não se deve palpar o local novamente. A fim de evitar o deslocamento da veia durante o procedimento, traciona-se a pele distal ao local da punção venosa com a mão não dominante. Insere-se o cateter na veia com o bisel voltado para cima em ângulo de 5 a 30 graus (quanto mais superficial a veia, menor o ângulo de inserção). Quando o cateter penetra o lúmen da veia, há refluxo de sangue. Uma vez que a agulha de metal e o cateter de plástico estão no lúmen da veia, avança-se o cateter em direção à veia, retirando a agulha simultaneamente. Após a inserção completa do cateter na veia, remove-se o garrote. Para evitar perda de sangue pelo cateter de plástico após a remoção da agulha, aplica-se pressão direta à veia, proximal à extremidade do cateter. Para confirmar que o cateter está pérvio, injeta-se soro fisiológico através dele, observando a ocorrência de edema, vermelhidão, extravasamento ao redor do local de inserção ou desconforto. Após a confirmação da permeabilidade do cateter, conecta-se o equipo de soro e inicia-se a infusão. Faz-se, então, a fixação do cateter com curativo oclusivo, de preferência transparente e estéril, e fixase o equipo em alça, anotando a data no curativo. ${ }^{2}$

As complicações mais comuns da cateterização venosa periférica são dor, formação de hematoma, infecção bacteriana, extravasamento de fluidos e drogas, flebite, trombose, embolia e lesão nervosa. A seleção de cateteres de tamanhos apropriados, a técnica de inserção estéril e a administração de líquidos e drogas em quantidades e concentrações adequadas podem prevenir estas complicações. ${ }^{2,3}$

\section{Acesso vascular Intraósseo}

A cateterização intraóssea proporciona acesso ao plexo venoso da medula óssea, que se conecta com a circulação venosa sistêmica, constituindo via rápida, segura e confiável para a administração de fluidos (cristaloides ou coloides), drogas e hemoderivados durante a ressuscitação. Pela via intraóssea, é possível também administrar drogas vasoativas por infusão contínua. Além disso, o acesso intraósseo possibilita a coleta de sangue venoso para análise laboratorial. ${ }^{1,3,4}$

$\mathrm{O}$ acesso intraósseo pode ser estabelecido mais rapidamente que o acesso venoso central, usualmente em 30 a 60 segundos, e é indicado quando não se consegue obter o acesso venoso periférico prontamente em pacientes em choque, insuficiência respiratória, ou parada cardiorrespiratória. ${ }^{1}$

As contraindicações à obtenção do acesso intraósseo incluem fratura no osso a ser puncionado, presença de dispositivo ortopédico ou prótese no membro, infecção de pele ou partes moles subjacentes ao local de inserção e doenças ósseas (osteogênese imperfeita, osteopenia e osteopetrose). Além disso, havendo insucesso na obtenção do acesso intraósseo após uma tentativa, uma nova punção no mesmo osso não deve ser tentada, pois as medicações e os fluidos infundidos podem não atingir a circulação central, além de poderem extravasar, levando à síndrome de compartimento. . $^{1,3,4}$

Há vários tipos de agulhas desenvolvidas especificamente para punção intraóssea em crianças. Elas são constituídas de uma cânula externa e de um estilete cortante interno, e possuem alças ergonômicas para facilitar sua colocação (Figura 3).

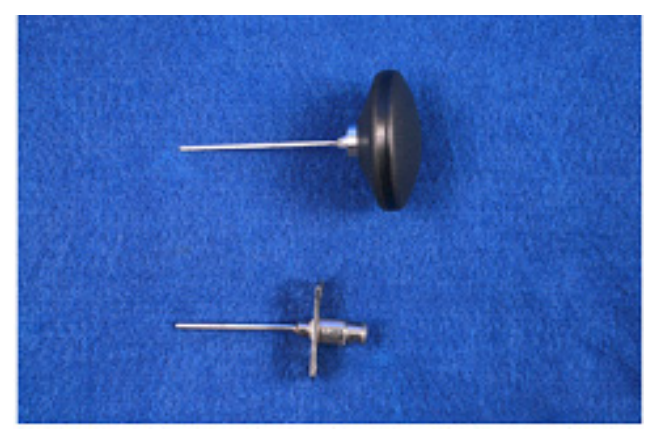

Figura 3: Agulha para infusão intraóssea contendo estilete cortante interno (acima) e cânula externa (abaixo).

Caso a agulha intraóssea não esteja disponível, agulhas comuns de grosso calibre (16 gauge) ou do tipo butterfly podem ser utilizadas em lactentes, mas elas podem obstruir com osso ou medula óssea. Dispositivos do tipo mola ou broca foram desenvolvidos para facilitar a colocação da agulha intraóssea em crianças e adultos. ${ }^{4,5}$ 
Vários locais anatômicos podem ser usados para a cateterização intraóssea, incluindo a tíbia proximal, o fêmur distal, a tíbia distal, o úmero proximal e a crista ilíaca anterossuperior. ${ }^{1,4}$ Em adultos, o esterno e o rádio distal também podem ser utilizados. ${ }^{5} \mathrm{~A}$ tíbia proximal é o local de escolha em crianças, pois os pontos de referência podem ser facilmente identificados, além de ser distante da cabeça e do tórax, não interferindo com as manobras de ressuscitação cardiopulmonar. ${ }^{1,4}$

A técnica de obtenção do acesso intraósseo é descrita a seguir. Inicialmente, posiciona-se o paciente de forma a tornar o local de inserção facilmente acessível. Em crianças, a agulha intraóssea é inserida, mais comumente, no platô tibial, 1 a $3 \mathrm{~cm}$ abaixo e medial à tuberosidade da tíbia (Figura 4). ${ }^{1}$

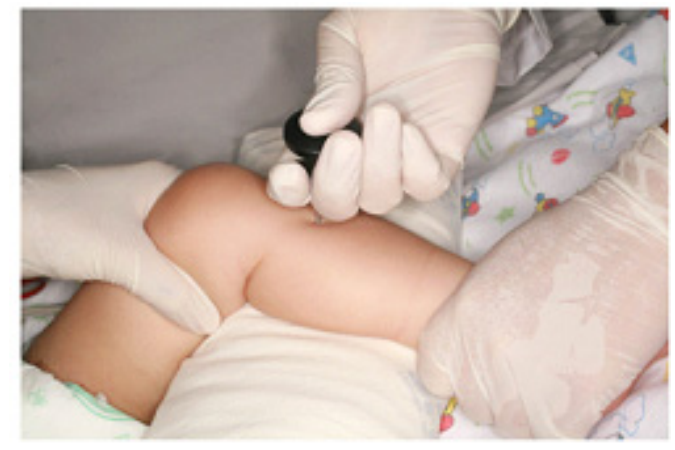

Figura 4: Local do acesso intraósseo na tíbia proximal.

Na tíbia distal, o local de inserção é a superfície anterior, $1 \mathrm{a} 2 \mathrm{~cm}$ acima da margem superior do maléolo medial. No fêmur distal, a agulha deve ser inserida na linha média, 1 a $3 \mathrm{~cm}$ acima da patela. Quando o local escolhido para a punção é a tíbia proximal ou o fêmur distal, coloca-se uma toalha enrolada sob a fossa poplítea, para ajudar a manter a flexão do joelho e a estabilidade da perna. Utilizando técnica asséptica, faz-se a limpeza do local de inserção da agulha com solução de clorexidina ou iodopovidona. Em pacientes acordados e alertas, recomenda-se fazer anestesia local com lidocaína. Após fixar bem o membro, com a mão não dominante distal ao local de inserção (evitando que a mão do profissional fique atrás do ponto de inserção, para evitar acidentes), insere-se a agulha perpendicularmente ao plano do osso, realizando movimentos de rotação e pressão, até se sentir diminuição da resistência ao atravessar a tábua óssea. Considera-se que a agulha esteja bem posicionada se ela se mantiver ereta, sem necessidade de sustentação, e ao infundir solução salina, não houver resistência nem tumefação de partes moles. Eventualmente, à aspiração da agulha obtém-se material medular, mas isto nem sempre acontece. A amostra de medula obtida à aspiração pode ser enviada para análise da concentração de glicose, cultura, tipo sanguíneo, eletrólitos e gasometria venosa, mas não para hemograma completo, pois as células imaturas da medula óssea não refletem com precisão os achados da circulação periférica. Fixa-se, então, a agulha com esparadrapo, protegendo-a com curativo oclusivo e conecta-se o equipo de soro.

Para vencer a resistência da cavidade medular à infusão inicial de fluidos, pode-se administrar salina em bolus com seringa, bolsa pressórica ou bomba de infusão. Para evitar complicações, o acesso intraósseo deve ser removido assim que se obtiver um acesso venoso mais definitivo, de preferência até 24 horas após sua inserção. ${ }^{1,3,4}$

Complicações sérias associadas ao acesso intraósseo são raras; a mais comum é o extravasamento de fluido em partes moles secundário à colocação incorreta do cateter. Se não reconhecido, o extravasamento prolongado de líquido pode levar à síndrome de compartimento. Outras complicações incluem infecção no local de inserção (osso ou partes moles), fraturas (especialmente em lactentes jovens ou pacientes com osteopenia), lesão da cartilagem de crescimento e embolia gordurosa. ${ }^{4}$

\section{Acesso venoso central}

A cateterização venosa central proporciona acesso mais seguro à circulação sistêmica e permite a administração de medicamentos que podem lesar tecidos quando ocorre extravasamento a partir de um acesso venoso periférico, como vasopressores e soluções hipertônicas de bicarbonato de sódio e cálcio. Além disso, o acesso venoso central possibilita a monitorização da pressão venosa central e a coleta de amostras de sangue. As contraindicações gerais da colocação de um cateter venoso central incluem infecção da área subjacente ao local de inserção e trombose da veia em questão. Coagulopatia constitui contraindicação relativa. Cabe salientar que o trauma pode distorcer a anatomia e dificultar a colocação de um cateter venoso central na região. ${ }^{6}$

Antes de iniciar o cateterismo venoso central, devem-se adotar as precauções universais, ressaltando-se a importância da lavagem das mãos e da ado- 
ção das precauções de barreira completa (máscara, gorro, avental cirúrgico, luvas estéreis e campos estéreis). ${ }^{3,6}$

A opção por determinada veia ou via de acesso se dá de acordo com a experiência de quem realiza o procedimento e as características do paciente. Em crianças, as veias jugulares internas e as femorais são as mais frequentemente cateterizadas e em adultos, a veia subclávia é a via de escolha para colocação de um cateter venoso central. Durante a RCP, deve-se dar preferência às veias femorais, pois sua obtenção não interfere com as manobras de ressuscitação. ${ }^{1,6}$

Além dos equipamentos de proteção individual, o material necessário para a inserção de cateteres venosos centrais inclui bolsa e equipo de soro, anestésico local, campo estéril, gaze estéril, bisturi, kit de cateter central (contendo agulha, fio guia, dilatador e cateter intravenoso) (Figura 5), agulha e fio para fixação do cateter à pele e curativo transparente estéril.

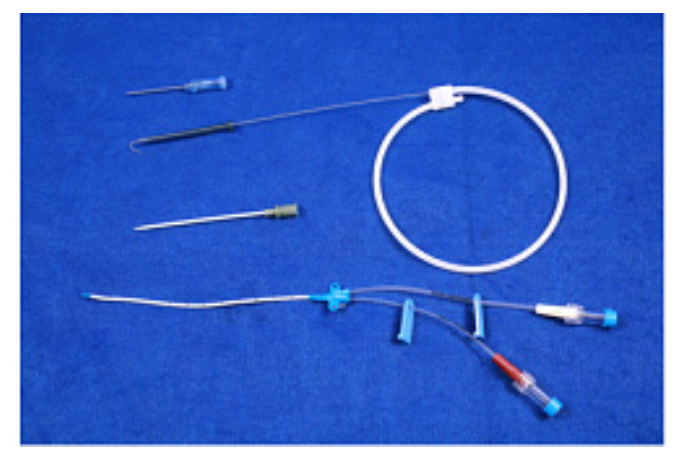

Figura 5: Kit de cateter de duplo lúmen contendo (de cima para baixo) agulha, fio guia, dilatador e cateter de duplo lúmen.

Os cateteres mais comumente utilizados são os de calibre 5 French para recém-nascidos, 7 French para lactentes e 8 a 11 French para crianças maiores e adultos. O comprimento do cateter deve ser determinado pela profundidade de inserção em relação aos pontos de referência anatômicos do paciente. Como o risco de infecção aumenta proporcionalmente ao número de lúmens, o cateter deve conter o menor número de lúmens necessário. 3,6

\section{Veia jugular interna}

O local de referência é o triângulo de Sedillot, formado em sua base pela clavícula e lateralmente pelas porções esternal e clavicular do músculo esternocleidomastoideo (Figura 6). ${ }^{3}$
Inicialmente, posiciona-se o paciente em decúbito dorsal horizontal com a cabeça para baixo a $30^{\circ}$, em posição de Trendelenburg, com coxim abaixo das escápulas, deixando a cabeça levemente estendida e rodada para lado oposto ao da punção. Dá-se preferência ao lado direito, pois as complicações como pneumotórax, hemotórax e quilotórax são mais frequentes após tentativas de punção do lado esquerdo. Isto ocorre porque o ápice do pulmão é mais alto à esquerda do que à direita e o ducto torácico se localiza à esquerda. Além disso, o caminho entre a veia jugular interna direita e o átrio direito é mais direto. Antes de iniciar o procedimento, ausculta-se o tórax para verificar se o murmúrio vesicular é simétrico bilateralmente. Após o posicionamento do paciente, faz-se a degermação da pele com clorexidina degermante, seguida de antissepsia com clorexidina alcoólica, em movimentos circulares do centro para a periferia e coloca-se um campo estéril. Administra-se, então, anestésico local ( 1 a $2 \mathrm{ml}$ de lidocaína $1 \%$ ) com agulha 25 gauge no local da cateterização e procede-se à punção. .,3,6 $^{1}$

Utiliza-se a técnica de Seldinger para a obtenção do acesso venoso central. A seguir, descreve-se a cateterização da veia jugular interna pela via central. $\mathrm{O}$ procedimento se inicia pela introdução da agulha pouco acima do ápice do triângulo em ângulo de $30 \mathrm{a}$ 45 graus em relação ao plano coronal, em direção ao mamilo ipsilateral, aplicando sucção leve. Ao atingir a veia, desconecta-se a seringa, ocluindo a extremidade proximal da agulha com o dedo e introduz-se o fio guia por dentro da agulha, avançando-o bem além da ponta da agulha. Caso haja batimentos cardíacos ectópicos no monitor, traciona-se o fio guia até que os batimentos ectópicos desapareçam. Remove-se, então, a agulha, mantendo o fio guia inserido. Faz-se uma

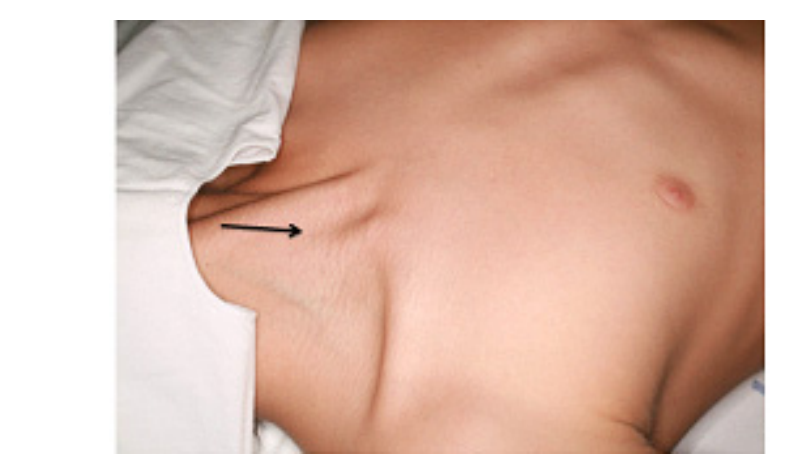

Figura 6: Triângulo de Sedillot formado em sua base pela clavícula e lateralmente pelas porções esternal e clavicular do músculo esternocleidomastoideo. A seta aponta o local de referência para a punção da veia jugular interna. 
incisão de 1 a $2 \mathrm{~mm}$ no local da punção na pele e introduz-se o dilatador sobre o fio guia. Após a dilatação do trajeto, remove-se o dilatador e introduz-se o cateter sobre o guia na veia. Remove-se o fio guia e após visualizar o retorno de sangue, conecta-se o cateter ao equipo com soro fisiológico $0,9 \%$. O retorno de sangue deve ser verificado pela aspiração de cada via do cateter. Alternativamente, coloca-se a bolsa de soro abaixo do nível do átrio direito para permitir que o sangue reflua até o equipo de soro, antes de iniciar a infusão pelo cateter. Se não houver retorno de sangue, a ponta do cateter pode estar alojada contra a parede do vaso ou do átrio direito. Nesta situação, traciona-se o cateter levemente e repete-se a aspiração. Se ainda assim não houver retorno de sangue, deve-se presumir que o cateter não esteja na veia e, desta forma, ele deve ser removido. O fio guia deve ser utilizado para medir as distâncias: para posição central, a extremidade do cateter deve estar no átrio direito, o que corresponde externamente ao $2^{\circ}$ ou $3^{\circ}$ espaço intercostal à direita. Fixa-se, subsequentemente, o cateter com fio de algodão e aplica-se curativo estéril. Após o término do procedimento, deve ser feita uma radiografia para verificar a posição do cateter. ${ }^{6}$

Outras duas vias de acesso podem ser utilizadas para a cateterização da veia jugular interna: a anterior e a posterior. A punção da veia pela via anterior é feita na borda anterior do músculo esternocleidomastoideo, na porção média entre a mastoide e a clavícula, em direção à base do triângulo, com angulação de 30 graus. Pela via posterior, a punção é feita na borda posterior do esternocleidomastoideo, ao nível da união de seu terço médio com o inferior, em direção à fúrcula esternal, com angulação de 30 graus em relação à pele. ${ }^{3}$

Recentemente, a ultrassonografia tem sido utilizada para guiar a inserção do cateter e diminuir o risco de complicações. A veia e a artéria aparecem com forma circular e cor escura na imagem do ultrassom, porém a veia é mais compressível quando se aplica pressão sobre a pele com o transdutor. A agulha é ecogênica e pode ser vista dentro da veia pelo ultrassom. ${ }^{6}$

\section{Veia femoral}

O paciente deve ser posicionado em decúbito dorsal horizontal, com a coxa fixada em ligeira rotação externa. Pode-se colocar um coxim sob a região lombo-sacral, para leve extensão. Após a administra- ção de anestésico local, identifica-se a artéria femoral pela palpação ou, se os pulsos estiverem ausentes, encontrando o ponto médio entre a crista ilíaca anterossuperior e a sínfise púbica. O ponto de referência para a punção da veia femoral é $5 \mathrm{~mm}$ medial ao pulso arterial e $2 \mathrm{a} 3 \mathrm{~cm}$ abaixo do ligamento inguinal. A agulha deve ser inserida neste ponto paralelamente à artéria femoral, em direção ao umbigo, com inclinação de 45 graus em relação ao plano da pele. Para prevenir a cateterização inadvertida da artéria femoral, mantém-se a palpação da artéria enquanto se introduz a agulha na veia. Havendo refluxo de sangue, desconecta-se a seringa e passa-se o fio guia através da agulha. Remove-se a agulha, faz-se pequena incisão na pele com bisturi, passa-se o dilatador sobre o fio guia e, subsequentemente, introduz-se o cateter sobre o fio guia, segundo a técnica de Seldinger. Após a fixação do cateter à pele, faz-se uma radiografia para verificar a posição de sua extremidade, que deve estar localizada na junção da veia cava inferior com o átrio direito ou na altura da segunda vértebra lombar, caso o comprimento do cateter não seja suficiente para atingir a posição central. ${ }^{7}$

\section{Veia subclávia}

Posiciona-se o paciente em decúbito dorsal horizontal com a cabeça em posição mediana inclinada para baixo a 30 graus (Trendelenburg), com o pescoço levemente estendido. O ponto de inserção do cateter é na junção do terço médio com o terço medial da clavícula. Após anestesia local, insere-se a agulha com ângulo de 30 graus em relação à pele até a passagem sob a clavícula (a agulha deve passar tangenciando a clavícula). A partir daí, a agulha é inclinada 10 a 15 graus e direcionada à fúrcula esternal. $\mathrm{O}$ cateter é inserido utilizando a técnica de Seldinger anteriormente descrita. $^{8}$

As complicações relacionadas à cateterização venosa central podem ser mecânicas, infecciosas e tromboembólicas. As complicações mecânicas incluem punção arterial, hematoma, pneumotórax e hemotórax (associados à cateterização de veia jugular interna e subclávia), arritmia e colocação imprópria do cateter. O uso do ultrassom para guiar a cateterização venosa central reduz o número de tentativas e o risco de complicações. ${ }^{1,6}$

As complicações infecciosas podem ser prevenidas pela lavagem das mãos e adoção de precauções de barreira completa durante a inserção do cate- 
ter, antissepsia da pele com clorexidina, revisão diária da necessidade do cateter e sua remoção imediata, quando ele não for mais necessário. ${ }^{6}$

As complicações trombóticas podem ocorrer desde o primeiro dia após a inserção do cateter, com risco potencial de tromboembolismo venoso. O local com o maior risco de trombose é a veia femoral. $\mathrm{O}$ tempo de permanência do cateter deve ser limitado ao mínimo necessário para diminuir o risco de trombose. ${ }^{6,7}$

\section{ABSTRACT}

This paper describes the priorities of vascular access in different clinical situations, the indications, contraindications, and complications of various types of vascular access, and the techniques for obtaining a peripheral venous, intraosseous and central venous access.

Keywords: Peripheral Venous Access. Intraosseous Vascular Access. Central Venous Access. Child.

\section{Referências Bibliográficas}

1. American Heart Association. PALS - Pediatric Advanced Life Support - Provider Manual, 2002.

2. Ortega R, Sekhar P, Song M, Hansen CJ, Peterson L. Peripheral intravenous cannulation. N Engl J Med. 2008; 359:e26.

3. Mega LL. Procedimentos em terapia intensiva. In: Carlotti APCPC, ed. Manual de Rotinas de Terapia Intensiva Pediátrica. Tecmedd, Ribeirão Preto, pp. 373-94, 2005.

4. Nagler J, Krauss B. Intraosseous catheter placement in children. N Engl J Med. 2011; 364:e14.
5. Day MW. Intraosseous devices for intravascular access in adult trauma patients. Crit Care Nurse. 2011; 31:76-90.

6. Graham AS, Ozment C, Tegtmeyer K, Lai S, Braner DAV. Central venous catheterization. N Engl J Med. 2007; 356:e21.

7. Tsui JY, Collins AB, White DW, Lai J, Tabas JA. Placement of a femoral venous catheter. N Engl J Med. 2007; 358:e30.

8. Braner DAV, Lai S, Eman S, Tegtmeyer K. Central venous catheterization - subclavian vein. N Engl J Med. 2007; 357:e26. 